\title{
SEXUALIDADE FEMININA: COMPREENDENDO SEU SIGNIFICADO
}

\author{
Thais de Oliveira Gozzo* \\ Suzete Maria Fustinoni** \\ Márcia Barbieri*** \\ Wilma de Moura Roher**** \\ Ivoneide Aparecida de Freitas ****
}

GOZZO, T.O.; FUSTINONI, S.M.; BARBIERI, M.; ROEHR, W.M.; FREITAS, I.A. Sexualidade feminina: compreendendo seu significado. Rev.latino-am.enfermagem, Ribeirão Preto, v. 8, n. 3, p. 84-90, julho 2000.

Para compreender o significado da sexualidade entre mulheres participantes do grupo de orientação sobre este tema em um serviço de planejamento familiar, foi realizado este estudo de natureza qualitativa com enfoque fenomenológico. Através das falas das participantes e de redução fenomenológica encontramos o tema central: vivendo a sexualidade. Os resultados permitiram-nos conhecer um pouco mais sobre o assunto uma vez que as mulheres que procuram o grupo ofazem com o objetivo de curar o seu problema, acreditando terem disfunções sexuais, fato que é desmistificado ao perceberem que apresentam dificuldades em vivenciar sua sexualidade.

Unitermos: sexo, comportamento sexual

\section{INTRODUÇÃO}

Por razões culturais o sexo até há algum tempo era visto somente como algo ligado a reprodução, o prazer era reprimido, por ser considerado pecaminoso ou moralmente condenável.

Hoje, o sexo é parte do cotidiano das pessoas não estando limitado à concepção, já que o prazer humano independe da reprodução, extrapolando também os aspectos orgânicos e associando-se a estes os fatores biopsicossociais. Neste sentido, surge a necessidade da sexualidade ser englobada e não relegada ao assistirmos alguém.

A marginalização da sexualidade tem raízes firmadas na história. Segundo GÓIS (1991, p.119) "somos educadas por mulheres, numa sociedade onde a virilidade e o prestígio do macho estão longe de serem apagados". A mesma autora afirma ainda que as mulheres são educadas para agirem como filhas e mães sem passar pelo estágio de mulher.

Outros autores como DIAMANTINO et al. (1993a, p.1017) são de opinião que a mulher brasileira desde que nasce é educada 'para dentro'. É criada para servir, para ser obediente, casar, respeitar seu marido, ter filhos, ser dona de casa, sujeitar-se a um trabalho exaustivo, sem folgas ou reconhecimento.

Segundo a mesma autora, a mulher, quando criança, deve ter bons modos e controle sobre sua vontade. $\mathrm{Na}$ adolescência, não é preparada para a vida, mas sim para negar o prazer, cheio de culpa, censura e medo. Nesta fase, as questões sobre sexo geram constrangimentos e são respondidas de maneira incompleta, quando são ignoradas. Se ela deseja algo mais, lhe vem inconsciente ou consciente a idéia de que não é certo.

DIAMANTINO et al. (1993b, p.1154), diz que é na menacme que a mulher vive a mais intensa atividade sexual, momento em que surge o maior número de problemas neste aspecto. Sua saúde não depende de fatores orgânicos isoladamente, mas do contexto sexual que viveu até então, somado a fatores externos à vida sexual.

Diante disto, pode-se mencionar a definição de sexualidade segundo a autora que "refere-se ao impulso e à emoção que a proximidade do sexo pode produzir,

\footnotetext{
* Enfermeira. Especialista em Enfermagem Obstétrica. Enfermeira da Maternidade Mater de Ribeirão Preto-SP

** Enfermeira. Professor Assistente da Disciplina Enfermagem Obstétrica do Departamento de Enfermagem da Universidade Federal de São Paulo

*** Enfermeira. Professor Adjunto da Disciplina Enfermagem Obstétrica do Departamento de Enfermagem da Universidade Federal de São Paulo

**** Psicólogas do Serviço de Planejamento Familiar da Universidade Federal de São Paulo
} 
transcende definições físicas e se coloca como algo mais difuso permeando todos os momentos da vida".

De acordo com LAPLANCHE (1995, p.619) “... sexualidade não designa apenas as atividades e o prazer que dependem do funcionamento do aparelho genital, mas de toda uma série de excitações e de atividades presentes desde a infância, que proporcionam um prazer irredutível à satisfação de uma necessidade fisiológica fundamental e que se encontram a título de componentes na chamada forma normal do amor sexual".

Neste contexto cultural, pode-se comprovar que quando algum problema relacionado à sexualidade aflige as mulheres, elas não têm a quem recorrer. Quando a queixa é feita aos profissionais que atuam na área de saúde, estes mostram falta de interesse, tendo a sensação de que a sexualidade não faz parte da sua saúde.

No setor de Planejamento Familiar da Universidade Federal de São Paulo, em funcionamento há 23 anos, a proximidade a esta questão fez-nos refletir, além da dificuldade em abordar o assunto, o porquê as mulheres têm tantas queixas relacionadas com sua sexualidade.

Um ponto em comum de toda a assistência prestada ao longo dos anos, foi a constatação de que as usuárias apresentavam importante necessidade de informação sobre este assunto. Muitas queixas foram recebidas pelos profissionais nos diferentes atendimentos realizados.

A partir de então, surgiu o Grupo de Orientação sobre Sexualidade com o objetivo de conhecer as principais queixas das participantes em relação à sua própria sexualidade, criar um espaço para manifestar, trocar e refletir aspectos relevantes da sexualidade feminina, procurando, também, propiciar esclarecimentos pessoais sobre as dificuldades ali apresentadas.

Diante desta problemática e, a partir das situações vivenciadas pela equipe, decidimos realizar este estudo, com o objetivo de compreender o significado que as mulheres que participam do grupo de orientação sobre sexualidade do serviço de planejamento familiar dão à sua própria sexualidade. Pretendemos com seus resultados contribuir com os profissionais que no seu cotidiano lidam ou assistem mulheres para que atribuam as queixas sexuais a importância que elas merecem.

\section{A TRAJETÓRIA METODOLÓGICA}

Frente a vivência sexual das mulheres participantes do grupo era preciso uma forma de trabalho que englobasse os sentimentos, os valores individuais, a maneira como elas próprias percebiam sua sexualidade.

Optamos pela pesquisa qualitativa, já que esta não se define por números, mais sim por abranger experiências humanas e dar-lhes significados além de permitir uma visão holística dos indivíduos, associada ao estilo de vida e valores de cada sujeito.

Segundo GELAIN (1991, p. 61) "a pesquisa qualitativa identifica as características, os significados das experiências humanas que são descritas pelos sujeitos e interpretadas pelo pesquisador em vários níveis de abstração".

Dentro do tipo de pesquisa escolhido, adotamos o Enfoque Fenomenológico, que de acordo com FORGUIERI (1990, p.8) "é aquele que abarca o existir humano em sua totalidade, abrangendo a tristeza e a alegria, a angústia e a tranqüilidade, a raiva e o amor, a vida e a morte como pólos que se articulam numa única estrutura, e cuja vivência dá a cada um dos extremos, aparentemente opostos, o seu real significado".

Para a mesma autora, este enfoque vê o homem como um ser-no-mundo, que vivência o tempo presente, relacionando este às experiências passadas e o que espera do futuro. "A consciência que a pessoa tem de que seu próprio existir e os significados que as situações tem para ela, constituem uma experiência íntima".

Ao fazerem parte do grupo, as mulheres eram informadas de que suas falas seriam transcritas durante o transcorrer da reunião e o resultado, isto é, o discurso seria utilizado para o presente estudo garantindo anonimato e sigilo. Todas as participantes dispuseramse voluntariamente em participar.

\section{PROCEDIMENTO DA PESQUISA}

Para realização do presente estudo, foi utilizado o livro de registros dos dados do grupo de orientação, onde escolheu-se, de modo aleatório, duas reuniões, com a participação de 8 mulheres.

No livro deveriam estar registradas as respostas das mulheres para as 6 perguntas que comumente são abordadas: O que você pensa sobre a sexualidade? Qual a sua dificuldade em relação a sexualidade? O que você está fazendo para mudar? O que existe de bom no seu relacionamento conjugal? O que você espera alcançar participando deste grupo? Dê uma mensagem.

A análise dos dados foi realizada a partir do método de FORGUIERI (1997, p.15) utilizando a estratégia da Redução Fenomenológica empregada para atingir a essência do fenômeno.

Para realizar o estudo, cada depoimento foi lido e relido atentamente, obtendo-se as frases que estavam diretamente relacionadas ao fenômeno em questão, sendo agrupadas por suas semelhanças e significado comum. As unidades de significado, quando agrupadas, formaram os subtemas de onde destacou-se um tema. 
As participantes do grupo relataram o que pensavam, como percebiam e viviam sua sexualidade, que passavam por momentos de dificuldade em relação a ela, buscavam mudanças e refletiam sobre seu relacionamento com os companheiros. No grupo, procuravam elementos para que conseguissem melhorar este relacionamento e compartilharam experiências com as outras participantes.

Das falas das participantes foi possível a identificação de um tema relacionado ao objetivo proposto que foi vivendo a sexualidade, resultante da análise dos discursos e destas reflexões, foram extraídos seis subtemas, a seguir apresentados.

Pensando sobre a sexualidade acreditam que as demonstrações de afeto expressas através de gestos como carinho, beijo, abraço, e ações que envolvam ser tocada no lugar certo e sentir o companheiro, são parte da sexualidade.

Reconhecem a importância da compreensão, conversa, entendimento, diálogo como meio de sentir a participação do companheiro no relacionamento e na contracepção. Prezam o romantismo e a fantasia como meio de expressar e viver a sexualidade.

As participantes referem que atração, vontade de ter relação, sentir prazer, dar e receber prazer estão incluídos na sexualidade e acreditam que gostar do parceiro é importante também.

As mulheres relatam que o sexo é importante dentro e fora do casamento como um aspecto da sexualidade humana dizendo que saber o que o outro gosta na relação, não importando se há casamento ou não.

Sentindo dificuldade quanto a sexualidade refletem sobre como percebem e compreendem as limitações, as inseguranças e as preocupações na vivência de cada um frente à sexualidade.

As mulheres relatam que sentem dificuldade no relacionamento íntimo por se sentirem frias e geladas; por medo de engravidar, por dificuldade em expressar suas necessidades afetivas tenho dificuldade de falar o que sinto, vergonha de dar dicas de onde ser tocada, de falar o que querem na relação.

As participantes percebem que essas dificuldades incluem também o comportamento e as atitudes dos companheiros. O que pode ser salientado quando elas dizem que têm grande dificuldade em dialogar com o companheiro, no que se refere aos problemas dele porque o marido não aceita que converse sobre seus problemas ou os do dia-a-dia do casal e dos filhos. Acrescentam que a mágoa está interferindo na relação sexual, não gosto de ser tocada. Acho que meu marido só quer saber de sexo o resto não interessa, está interferindo na sexualidade.

Também colocam que o meu filho não deixa eu ficar com meu marido, ele tem ciúmes de mim interfere no relacionamento conjugal.

Quando essas mulheres participam do Grupo de Orientação sobre Sexualidade é porque, na maioria das vezes, estão tentando mudar. Assim, as participantes colocam que para isso estão procurando ajuda ou estão procurando pensar e agradar mais o marido fazendo o que elas sabem que ele gosta, como coloco uma camisola que ele goste, estou tentando perder a timidez, ser mais carinhosa e tentar tomar iniciativa para a relação sexual quando percebe que ele quer. Procura terminar logo seus afazeres para dividir sua atenção e conversar com o filho e com o marido.

Quando as mulheres são indagadas como estão percebendo o seu relacionamento, a grande maioria ressalta as características físicas e morais destes como ele trata bem meu filho, é carinhoso, compreensivo, tem físico bonito, não tem vícios, é atraente, e não sobre o próprio relacionamento. Entretanto houve quem dissesse que não existe, não sei porque ainda estou casada só o filho, o resto nada.

Em relação a sua participação no grupo elas referem que sentem esperança, por acreditar ali encontrar os elementos que procuram para mudar, tentando aprender coisas novas, conhecer melhor o companheiro e a si própria, sentir desejo, aprender novas formas de relação sexual, ter maior satisfação e levar experiências, para assim conseguir melhorar o relacionamento conjugal.

É também uma das esperanças que se tem participando do grupo tentar uma solução para não desistir dele ou de qualquer outro homem.

Para finalização do grupo, as participantes compartilhando vivências tentam ajudar umas as outras naquilo que colocaram sobre suas vidas. Acham que descobrir seu corpo, esquentar sua mente e seu corpo, tem que se abrir cada vez mais para sentir prazer pode auxiliar nas mudanças no relacionamento conjugal que estão procurando.

Dizem ainda que buscar outras formas de sentir prazer como ir a motel, assistir filmes pornô, mostrar que ele tem duas mãos e que pode te dar prazer pode também ajudar.

Tentar conversar com o marido dizendo o que tem vontade, não ter vergonha de dizer o que pensa são outras opções que as participantes sugerem para melhorar o relacionamento com o companheiro.

Descobrir o que sente pelo marido foi colocado pelas participantes como um meio de conseguir mudar através da fala descubra que você ama seu marido. 
Ao tentar compreender como as participantes do grupo de Orientação vivenciam sua sexualidade, passamos a buscar subsídios para conhecer um pouco mais sobre o que se refere a sexualidade, em especial a feminina, para assim conseguir atingir o objetivo proposto.

A grandiosidade do sexo vai além da satisfação física do desejo e da sensação de prazer alcançada e também não deve ser considerada como meio exclusivo do casal obter felicidade. $\mathrm{O}$ vínculo deve ser fortalecido pelo respeito, amor, carinho, levando a um relacionamento íntimo mais prazeroso, e assim satisfazendo ambos os cônjuges (DIAMANTINO et al., 1993b, p.1174).

A relação sexual na espécie humana é uma necessidade básica, não instintiva, razão pela qual o indivíduo decide se quer ou não praticá-la.

Esses pontos mencionados podem ser observados concretamente quando as participantes do grupo, pensando sobre a sua sexualidade, definem o que acreditam dela fazer parte. Demonstram através de suas falas que gostar do companheiro é um elemento facilitador para a expressão da sexualidade já que este sentimento pode ser manifestado, também, através do contato físico que é desencadeado por sentir desejo e atração pelo companheiro que levam ao sexo propriamente dito, são somente alguns aspectos para viverem a sexualidade.

O prazer do casal, seria conseqüência de uma relação sexual satisfatória independente de haver ou não intenção de reprodução no ato sexual.

Citam a importância da fantasia e do romantismo liberando desejos que a razão reprime, deixando de lado as imposições e limitações estipuladas pela cultura.

A visão feminina de fantasia, é de uma vida sexual satisfatória. Para a mulher qualquer que seja sua imagem, ela deve vir sempre vinculada ao romantismo. Neste contexto, fazem parte as demonstrações de afeto expressas das mais variadas formas e em diferentes momentos, o diálogo e a compreensão citadas pelas participantes do grupo como sendo parte importante e elemento facilitador da expressão da sexualidade.

Em relação a categoria sentindo dificuldade quanto a sexualidade é percebido e debatido pelas participantes do grupo quando o conceito e as expectativas que elas têm sobre o sexo e o relacionamento com o companheiro entram em conflito. Isto se dá, provavelmente, porque as expectativas da mulher relacionadas ao amor, implicam em preocupar-se com o bem estar e com o prazer do outro, fazê-lo sentir-se único, e com ela compartilhar as responsabilidades do casal.
As dificuldades em exercer a sexualidade, vem das escolhas feitas pelos indivíduos, quando estes sacrificam aspectos próprios para atenderem as exigências da educação e da cultura, por exemplo a cultura brasileira cultua a figura masculina e educa a mulher para servir o homem sem preocupar-se consigo mesma. Por outro lado, pode significar busca de algo que não se realiza. Daí a afirmação "nem tudo deve ser patologizado, mas compreendido em sua essência"(CARIDADE, 1995, p.3).

Neste momento as participantes referem-se as limitações da sexualidade como nunca ter sentido prazer. Este fato está muito relacionado com a expectativa que as mulheres vão para uma relação sexual, tendo o orgasmo como um compromisso ou um objetivo a ser atingido, ou baseado no que as outras mulheres descrevem como orgasmo. Esse "querer chegar" dificulta ainda mais porque acabam esquecendo do antes e o durante na relação, não permitindo que as coisas aconteçam naturalmente. Cada mulher deve buscar sua maneira de sentir prazer e como chegar ao seu ápice.

No aspecto de nunca ter sentido amor por ninguém com quem se relacionou, percebe-se que a união sempre se dá com expectativas mútuas. Por outro lado, apresentam uma postura imediatista, não dando tempo para o processo do amor. No entanto, as próprias mulheres colocaram anteriormente alguns aspectos tais como: o envolvimento, o comprometimento e a perspectiva de amor como propiciadores da intimidade e do prazer do casal.

Um elemento facilitador da sexualidade citado anteriormente pelas participantes foi o diálogo, entretanto neste momento acaba sendo um obstáculo para o bem relacionamento do casal, observado quando elas referem que estão sentindo dificuldade em dialogar com o companheiro.

Essa falta de diálogo é tanto em relação aos problemas do casal, quanto em relação à sexualidade onde o homem desconhece as formas de excitar a mulher e esta parte do pensamento que o homem sabe tudo em relação ao sexo, ele não verbaliza que carícias gostaria de receber. Por outro lado, as mulheres tem a sensação de que é impróprio dizer ao homem o que ela gosta, temendo que ele se ofenda (DIAMANTINO et al., 1993b, p. 1172; FUCS, 1992, p. 60).

Ao perceberem que sentem dificuldade no relacionamento íntimo, associam este a felicidade da união conjugal à satisfação sexual. $\mathrm{O}$ não fortalecimento do vínculo e este relacionamento pode levar a uma situação de crise afetando a vida conjugal, ocorrida pela falta de abertura no diálogo entre os parceiros não levando assim a uma relação satisfatória.

Culturalmente a mulher brasileira é vista como objeto de prazer, e se pensarmos que no ato sexual se busca dar e receber carinho, compartilhar e proporcionar 
prazer para ambos, nem sempre é o que a mulher encontra (DIAMANTINO et al., 1993a, p. 1018).

Isto pode ser notado quando as participantes afirmam que o companheiro só se interessa por sexo ou o companheiro não se preocupa com seu prazer sexual, a maioria deles credita que para a mulher a penetração é suficiente para atingir o orgasmo, mas ocorre o oposto, o contato para a mulher deve ser mais íntimo, cuidadoso, porque tem sensações no corpo como um todo, daí a necessidade maior do estímulo tátil do que somente a penetração. A visão individualista do homem voltada para o seu prazer, para alguns egoísmo e para outras somente falta de informação sobre o prazer feminino, pode representar situação de crise afetando a vida conjugal e sexual do casal (FUCS, 1992, p.60; MONTGOMERY, 1997, p. 86).

O sentir mágoa do companheiro referido pelas participantes, pode ser uma conseqüência direta dos precários padrões de comunicação entre o casal, podendo levá-los também à frustração, ao afastamento e ao desinteresse. Atribuem o problema da relação ao parceiro, quando referem a ejaculação precoce como causadora dos conflitos e insatisfações no relacionamento conjugal, ou a outros quando referem-se ao ciúme do filho.

Ao ser discutido o subtema tentando mudar elas colocam que estão procurando ajuda, procurando agradar e pensar mais no marido, esperando que seu companheiro tome iniciativas, negando seu próprio ser, pensando o que fazer e que não está fazendo nada constituem alternativas para melhorar sua vida conjugal, sem contudo pensar ou criar meios de satisfazer as suas próprias necessidades.

Ao serem questionadas sobre como estão percebendo seu relacionamento referem que não existe nada de bom ou que existe somente o filho, não se dando conta da sua própria responsabilidade no vínculo conjugal perpetuado em muitas delas a vários anos de convivência.

Isto é reforçado ao referirem que sentem esperança pois a grande maioria das participantes esperam conseguir mudar. Buscam mudanças nos mais variados aspectos, como aprender mais sobre o seu corpo e assim ter mais desejo, satisfação e diferenciar as formas de relação sexual.

Colocam também que ao estabelecer intimidade e abertura entre os parceiros, há condições de melhorar o relacionamento conjugal para que haja uma verdadeira interação entre eles e encontrar solução para não desistir do relacionamento.

$\mathrm{Na}$ finalização do grupo, compartilhando vivências, as participantes sugerem buscar outras formas de sentir prazer ou meios que favoreçam, como elas mesmas referem, que permitam conhecer o seu corpo e aprender a gostar dele, tentar conversar com o marido, perder a timidez, tentar sentir prazer ou tentar dar prazer, assim mostrar ao companheiro, mais facilmente, as regiões que gosta de ser tocada e que ela pode ter prazer sem necessariamente ter penetração, e reduzindo, desta forma, a ansiedade do parceiro, mostrando a ele que o melhor da relação sexual é ficar junto o maior tempo possível, e aproveitar o momento.

Sugerem que ao mudar de método anticoncepcional, as relações sexuais serão mais satisfatórias. A adequação do método, independente da idade, é aquele que melhor se adapte à mulher e ao casal. Neste sentido, se a mulher se sente segura o casal estará mais livre para viver a sexualidade do ponto de vista afetivo, emocional e do prazer.

Outra alternativa apontada para satisfação de suas necessidades sexuais e afetivas é a de tirar o filho do quarto do casal a fim de proporcionar privacidade, pois sem esta atitude o casal tem menores chances de conseguir relaxamento físico e mental, o que vai tornando cada vez mais esporádica a atividade sexual.

Ao sugerirem tentar resolver o problema do filho, verifica-se que este tornou-se um derivado das dificuldades do relacionamento com o companheiro. Neste aspecto, as mulheres podem estar se percebendo e melhorando sua vida conjugal.

\section{DESCRIÇÃO DO FENÔMENO}

Analisando o tema Vivendo a Sexualidade, identificado nas falas das participantes do grupo de orientação em sexualidade, percebemos que essas mulheres têm grande dificuldade no relacionamento com o companheiro no que se refere ao diálogo, em verbalizarem seus sentimentos e a se conhecerem interna e externamente.

No decorrer do grupo, as participantes são levadas a pensar sobre a sexualidade e a questionar seu relacionamento, para tentar encontrar o porquê de estarem sentindo dificuldades.

Pensando sobre sexualidade, as participantes refletem sobre o que é sexualidade para elas e percebem elementos que acreditam serem importantes na vivência desta. Constatam que além do sexo em si, é importante sentirem amor pelo companheiro e que este dê demonstrações de carinho, para que o casal consiga ter um relacionamento sexual satisfatório acompanhado de prazer

Na tentativa de compreender as limitações, as inseguranças e preocupações, é quando elas se percebem e relatam que estão sentindo dificuldade quanto à sexualidade. Sentem que não conseguem dialogar com o companheiro por vergonha de verbalizar as necessidades afetivas. 
Para tentar reverter essas dificuldades, ao participarem do Grupo de Orientação em Sexualidade, elas já estão tentando mudar. Esta mudança, no entanto, acontece de uma maneira que ressalta que o importante é satisfazer o companheiro deixando de lado a satisfação pessoal.

Diante desta realidade, acabam percebendo seu relacionamento onde a maioria destaca as características dos companheiros, e a minoria refere não existir nada ou melhor, como o único ponto positivo destaca a existência do filho.

Em oposição ao que percebem do relacionamento, elas sentem esperança participando dos grupos, por acreditarem que ali podem encontrar elementos para conseguirem as mudanças tão desejadas e assim melhorar o relacionamento conjugal.

Finalizando o grupo, as participantes compartilhando vivências procuram ajuda mútua, já que muitas vezes percebem problemas parecidos com o que estão vivendo.

\section{CONSIDERAÇÕES FINAIS}

A realização deste estudo, permitiu-nos conhecer um pouco mais sobre a sexualidade feminina, já que é um assunto vasto, que deriva várias abordagens e problemas no contexto sociocultural em que vive a mulher. Permitiu também refletir sobre a atuação da enfermagem neste aspecto.
As mulheres que participam deste grupo, procuram uma cura para o seu problema, acreditando ser uma disfunção sexual, fato que é desmistificado no desenrolar do grupo, onde elas acabam por perceber que apresentam sim uma dificuldade em viver a sexualidade.

O estudo revela como agravante nas dificuldades em relação à sexualidade, a falta de diálogo entre o casal. Embora cada um tenha a sua visão de mundo, existem situações que permitem conviver e compartilhar das mesmas experiências. Se a mulher não dividir o peso da educação dos filhos, os problemas de ordem financeira, e também ajudar o companheiro quando percebe que algo não vai bem, não conseguirá sentir-se bem numa relação sexual.

Cabe ao profissional de saúde tentar esclarecer as questões que essas mulheres têm nos mais variados atendimentos, já que as dificuldades em viver a sexualidade são mais comuns do que se pode imaginar. Entretanto, existe uma falta de abertura na assistência impossibilitando que se forme um vínculo entre cliente e profissional, não sendo possível a verbalização do problema.

Este aspecto pode ser amenizado, ou mesmo mudado, se o profissional destituir-se de valores morais próprios, e procurar conhecer e entender o contexto e os valores culturais/morais da população com quem trabalha; ouvir e partilhar suas impressões, opiniões e conhecimentos com a equipe e principalmente tentar compreender que o ser humano é histórico, se transforma, pensa e sente, recebe influências do meio em que vive e deve ser visto na sua totalidade.

\section{FEMALE SEXUALITY: UNDERSTANDING ITS MEANING}

The present qualitative study with a phenomenological focus aimed at understanding the meaning of female sexuality to women who participate in the activities of an orientation group about this subject, organized by a family planning service. Through the analysis of the participants speeches and phenomenological reduction, authors found the central subject: Living sexuality. Results allowed authors to learn a little more on this subject, especially considering that women who took part in this group aimed at solving their problem as they believed they had sexual disorders. However, this fact was demystified, enabling them to understand that they have problems in living their sexuality.

KEY WORDS: sex, sexual behavior

\section{SEXUALIDAD FEMENINA: COMPREDIENDO SU SIGNIFICADO}

Para comprender el significado de la sexualidad en mujeres participantes del grupo de orientación sobre este tema de servicio de planificación familiar fue realizado este estudio de naturaleza cualitativa con enfoque fenomenológico. A través de las conversaciones de las participantes y de la reducción fenomenológica encontramos el tema central: Viviendo la sexualidad. Los resultados nos permitieron conocer un poco más sobre el asunto una vez que las mujeres que nos buscaran lo hicieron con el objetivo de curar su problema creyendo tener disfunciones sexuales hecho que fue desmitificado al percibir que presentan dificultades para vivir su sexualidad. 


\section{REFERÊNCIAS BIBLIOGRÁFICAS}

01. CARIDADE, A. Abordagem corporal em terapia sexual. Recife, maio 1995. /Mimeografado.

02. DIAMANTINO, E.M.V. et al. Aspectos básicos da sexualidade humana na parte clínica. Parte I. Femina, v. 21, n. 10, p. 1016-29, 1993 a.

03. DIAMANTINO, E.M.V. et al. Aspectos básicos da sexualidade humana na parte clínica. Parte II. Femina, v. 21, n. 11, p. 1152-80, 1993 b.

04. FORGUIERI, Y.C. Contribuição da fenomenologia para o estudo de vivência. Rev.Bras. Pesq. Psicol., v. 2, n. 1, p. 7-20, 1990.

05. FORGUIERI, Y.C. Psicologia fenomenológica: fundamentos, método e pesquisa. São Paulo: Pioneira, 1997.
06. FUCS, B.G. Homem-mulher: encontros e desencontros. Crescimento da sexualidade através da relação. Rio de Janeiro: Rosa dos Tempos, 1992.

07. GELAIN, I. O significado do "ETHOS" e da consciência ética do enfermeiro em suas relações de trabalho. São Paulo, 1991. 147p. Tese (Doutorado) - Escola de Enfermagem, Universidade de São Paulo.

08. GÓIS, M.M.S. Aspectos históricos e sociais da anticoncepção. Reproduo, v. 6, n. 3, p. 119-24, 1991.

09. LAPLANCHE, J. Vida e morte em psicanálise. Porto Alegre: Artes Médicas, 1995.

10. MONTGOMERY, M. Mulher: o negro do mundo. Uma visão científica e humana do universo feminino. São Paulo: Gente, 1997. 